- Jürgen Bohnemeyer

UNIVERSITY AT BUFFALO-SUNY

\title{
Invisible Time Lines in the Fabric of Events: Temporal Coherence in Yucatec Narratives
}

This article examines how narratives are structured in a language in which event order is largely not coded. Yucatec Maya lacks both tense inflections and temporal connectives corresponding to English after and before. It is shown that the coding of events in Yucatec narratives is subject to a strict iconicity constraint within paragraph boundaries. Aspectual viewpoint shifting is used to reconcile iconicity preservation with the requirements of a more flexible narrative structure.

7 he fabric that constitutes the content of a narrative consists of a set of events and the relations that tie them together. Besides relations of causality, purpose, and so forth, time relations play a formidable role in narratives: anteriority, posteriority, simultaneity, and incidence. This situation gives rise to a mapping problem: The linear order of events in time must be mapped onto the equally linear order of clauses and sentences in discourse. The simplest solution is iconic mapping, in which the order of clauses mirrors the order of events (Figure 1):

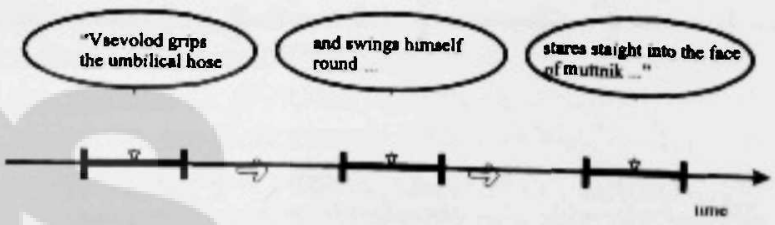

Figure 1

Iconic mapping of temporal events in narrative discourse. [Flint 1999:82] 
Many languages permit a more flexible mapping by using event-order relators, such as tenses and temporal connectives (Example 1):

(1) The week after the moon landing the BBC had broadcast a special Tomorrow's World show dedicated to the integrated circuit electronics which had made the Apollo missions possible. ... Hamish McCready took the audience on a tour of Cape Canaveral, showed them the enomous mainframe and the new mini-computers ... similar to the ones that Joel would begin to work with now that he was a post-graduate. [Flint 1999:109]

The simple past-tense forms in Example 1, took and showed, mark anterior order of the events referred to with respect to coding time and therefore indicate absolute tense (or deictic tense). The complex past tense forms had broadcast, had made, and would begin have an additional meaning that concerns the relative order of the events. This additional meaning is therefore often called relative tense (or anaphoric tense). On a traditional analysis now commonly associated with Reichenbach (1947), the pluperfect indicates that the event referred to precedes some reference point, while the future perfect indicates that the event follows a reference point. In Example 1, this reference point is the time singled out by the adverb now:' A temporal connective, after (occurring as a preposition in Example 1), indicates that the BBC show followed the moon landing. Each of these event-order operators encodes a relationship between two events or time intervals. The relationships are represented in Figure 2 by the heads and tails of arrows that are reflected (in a physical sense) by the operators encoding the relations. ${ }^{2}$

The use of event-order relators introduces into the narrative fabric explicit ("visible") timelines that free the representation of event order from the linear order of mention and, as Figure 2 illustrates, permit the fabric to become extremely complex. Moreover, they enable crucial thetorical structuring, such as backgrounding and foreshadowing. In fact, Example 1 represents nothing but backgrounded and foreshadowed eventsall that is said about the time marked by now is that the character Joel is in the state of being a postgraduate at this time.

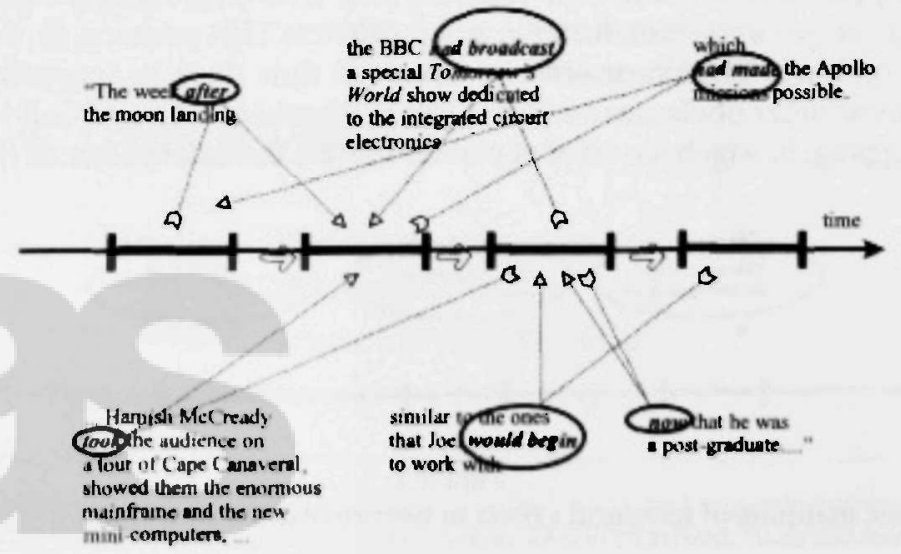

Figure 2

Noniconic mapping due to use of event-order operators. 
If event-order relators play such a major role in narrative structure, then how does a language that lacks such expressions compensate for their absence? And what consequences does this lack have for the structure of narratives? The test case studied in this article is Yucatec Maya, a native Mesoamerican language spoken on the Yucatan peninsula. Expressions of event order are almost entirely absent from the grammatical and lexical code of Yucatec. That is, there are no absolute or relative tenses and no temporal connectives translating after, before, or while. In the absence of verbal expressions, the communication of event order in Yucatec relies strongly on defeasible temporal inferences from aspectual and modal information. In Bohnemeyer 1998a, 1998b, and 2000, these inferences are analyzed as Gricean generalized conversational implicatures (GCIs). Inferences from aspectual or modal information to event order (that is, boundary-to-order inferences) are not particular to Yucatec; they are merely exploited to a greater extent than in Indo-European languages. The GCIs underlying these inferences can therefore be illustrated with English examples as well (Examples 2 and 3):

(2) a. Roberto sautéed some mushrooms and called Colette.

b. He called Colette after he sautéed the mushrooms.

(3) a. Mandana was working in her garden. Frank arrived.

b. Frank came while Mandana was working in her garden.

The use of the simple past tenses in Example 2a entails boundedness (or semantic perfectivity) of the two events of sautéing some mushrooms and calling Colette. The default interpretation of a combination of two events that are both presented as bounded is that these events are ordered sequentially. Accordingly, in the absence of further information, $2 \mathrm{a}$ implicates $2 \mathrm{~b}$. However, this is a rather weak implicature, as we have little reason to assume that it is impossible for Roberto to call Colette while he was preparing food, and there is nothing in the truth conditions of 2a that would be violated by this interpretation. Similarly, the use of the past progressive in the first clause in 3a represents the event of working in the garden as unbounded (or semantically imperfective). The combination of an event presented as unbounded and one that is presented as bounded is by default interpreted to the effect that the two events overlap. Specifically, the time of the event referred to as bounded is inferred to be included in the time of the event referred to as unbounded. Hence, 3a implicates $3 b$, even though 3a does not actually entail that Mandana continued working after Frank's appearance, but merely that Mandana had not completed her garden work before the time of Frank's arrival-so this too is clearly a defeasible inference. ${ }^{3}$

The Gricean analysis of temporal inferences presented in Bohnemeyer 1998a, $1998 \mathrm{~b}$, and 2000 is applied in this article to the problem of temporal coherence in narrative discourses of Yucatec. The discussion draws on examples from a folktale I recorded in the summer of 1999, but is based on a much larger corpus of narrative texts (for an inventory, see Bohnemeyer 1998b:140-143). The focus of attention is on the relationship between the order of the narrated events and the order of clauses and sentences in the text. Since the relevant expressions of event order are absent in Yucatec, disalignment between the order of events and the order of mention leads to incoherence, at least within paragraph boundaries. To this extent, narrative discourses in Yucatec are strictly iconic. The temporal inferences conveyed by aspectual (and modal) operators can be seen as a tool used by speakers and listeners to overcome the limitations imposed on the narrative by iconic representation of the order 
of events. Aspectual operators introduce different viewpoints on an event (cf. Comrie 1976; Smith 1991). Viewpoint shifts allow for accommodation of events that fall outside the main storyline to the iconic discourse structure. In more general terms, viewpoint shifts are, among other things, a means to map complex event representations constituted by relations of anterior, posterior, simultaneous, and incidental order to the simple unalterable sequence of clauses in discourse. Examples 4-7 illustrate this phenomenon, contrasting temporal clause constructions that code the event order with viewpoint-shifting aspectual operators that, in context, implicate the same event order. Example 4 illustrates coded versus implicated anterior order, 5 gives corresponding examples for posterior order, and coded versus implicated simultaneous and incidental order is exemplified in 6 and 7 , respectively:

(4) a. Anna defended her thesis after James gave a talk.

b. Anna defended her thesis. James had given a talk.

(5) a. James gave a talk before Anna defended her thesis.

b. James gave a talk. Anna was going to defend her thesis.

(6) a. Aaron smoked a cigarette while Birgit wrote her proposal.

b. Aaron smoked a cigarette. Birgit was writing her proposal.

(7) a. Birgit was writing her proposal when Aaron smoked a cigarette.

b. Birgit was writing her proposal. Aaron smoked a cigarette.

The next two sections provide a short sketch of the system of aspectual operators of Yucatec and analyze the use of these operators in one folk narrative.

\section{A Sketch of the Yucatec Aspect-Mood System}

Yucatec lacks expressions of event order almost entirely. The exceptions are:

- the deictic adverbs be'òora ... -a'/-e' 'now' and ka'ach(il) 'formerly'

- a set of terms locating days with respect to coding time: $k a^{\prime} j o$ 'oljeak 'the day before yesterday', jo'oljeak 'yesterday', beje'ela'. . . -e'/-a' 'today', sáamal 'tomorrow', and ka'abej 'the day after tomorrow'

- some phrases used as generic temporal anaphors, such as le káa tya'alajo' or le kéen ya'alo', both literally '(when) it said that', and ti' lelo', literally 'with respect to that' or 'at that'

However, these expressions are semantically and pragmatically restricted to a few clear-cut uses (see Bohnemeyer 1998b:443-504, 516-522). For instance, be'dora . . . -a'/-e' 'now' and ka'ach(il) 'formerly' do not directly locate events in time (e.g., they cannot be used in answers to 'when'-questions), but merely constrain the "topic time" (Klein 1994) for which propositions are asserted or questioned. They occur most frequently with stative predications and then implicate, but do not entail, confinement of the state at issue to the present or past. With verb clauses, these adverbs occur, for example, in counterfactual contexts, contexts of frustrated event realization, and contexts in which the result of some accomplishment did not last or is not expected to last (see examples in Bohnemeyer 1998b:450-460). The generic connective constructions simply indicate that the topic time for which a proposition is asserted or questioned is determined with respect to some time anaphorically tracked in discourse. They do not specify a particular ordering relation and are compatible with every event-order configuration. wWw.anthis source.net 
None of the expressions listed above has the capacity to locate any arbitrary event either with respect to coding time, as do the deictic or absolute tenses of Indo-European languages, or with respect to reference events in discourse, as do temporal connectives and anaphoric or relative tenses (cf. Comrie 1985, chpt. 3) in Indo-European languages. If one simply takes any of the four event-order relations of anteriority, posteriority, simultaneity, and incidence exemplified above and combines it with one of the three modes of grounding time reference-deictic, anaphoric, and calendrical-and then asks for a morpheme or construction in Yucatec whose meaning equals this combination (that, for example, expresses anteriority of any target event with respect to coding time, or posteriority of any target event with respect to a reference event in discourse), the answer has to be that there is no such morpheme or construction. In particular, none of the three types of event-order expressions introduced in the preceding section-absolute and relative tenses and temporal connectives-are instantiated in Yucatec. There are no absolute tenses that locate an event or time interval with respect to coding time, there are no relative tenses that locate an event or time interval with respect to a reference event or time interval given in discourse, and there are no connectives that express a specific event-order relation obtaining between an event or time interval and a reference event or time interval given in discourse. It goes without saying that a wealth of lexical and syntactic expressions must be carefully examined in order to validate such a claim - many more, certainly, than can be discussed here. However, the examination has been carried out (Bohnemeyer 1998a, 1998b, 2002; Vapnarsky 1999). Two of the more striking findings of this research merit brief mention here. One is the fact that spatial prepositions such as ich(il) 'in', 'inside' and relational nouns such as táan 'front', which, not surprisingly, have transferred temporal uses, nevertheless do not semantically encode event order. For example, an expression such as ich(il ti') $t s^{\prime} e^{\prime}$ 'ets'ek $k$ 'iin may be used to translate 'in a few days' (referring to an event in the [relative] future), '(with)in a few days' (referring to a time span within which some event was or will be completed), 'for a few days' (referring to the duration of a process or interval), or 'a few days ago', depending on aspect-mood marking. Bohnemeyer (1997) argues that this phenomenon is a confirmation of the localist hypothesis, according to which event-order relators are metaphorical path relators (cf. Clark 1973; Traugott 1978), albeit in a most unexpected way - as the Yucatec expressions in question, in their spatial uses, likewise fail to distinguish path relations. For instance, ich le najo' can mean 'in(side) the house', 'into the house', or 'out of the house', depending on the verb with which it is combined. The relational nouns taan 'front' and paach 'back', 'surroundings' produce adverbs táan-il and pàach-ill-al, which may be used in reference to the first and last place, respectively, in a sequence, including a sequence of events. However, just like English first and last, and unlike event-order relators such as after and before, táanil and pàachil do not take a reference event or interval as a second semantic argument; their referential ground is simply the sequence itself (see Bohnemeyer 1998b:469-484 for details).

The second fact concems a subset of the preverbal aspect-mood markers (see below), which serve to express "degrees of remoteness" in time (cf. Comrie 1985; Dahl 1984): proximate-future ta' itak, immediate-past táantik. . . - e', recent-past saam, and remote-past uuch. These occur with any reference point in the present, past, or future of coding time. That is, even the remote past marker may occur with absolute future time reference (as in By the time I finish revising this article, it will be long 
ago that I submitted it). Moreover, they also occur as lexical predicates; as such they simply denote the extension of time intervals. For example, úch-tal, literally 'to become a long time', can mean 'it is/was/will be long ago', 'it is/was/will be a long time before/until', 'it lasted/will last a long time', or 'it took/takes/will take a long time to complete', depending, again, on aspect-mood marking. Unlike these lexical occurrences, the expressions are not "symmetrical" when used as aspect-mood markers, but restricted to posterior reference points (i.e., relative past-time reference) in the case of the immediate, recent, and remote past markers and to anterior reference in the case of the proximate future marker. However, standard presupposition tests (cf. Bohnemeyer 1998b:433-442) show that unlike tenses, they do not encode this ordering relation, but merely presuppose it. Accordingly, in discourse, they are used to quantify the distance to the reference point, not to denote event order with respect to it. For the same reason, they are incompatible with event-time adverbials and are excluded from occurrence in content questions about event times (i.e., 'when'-questions).

At the same time, Yucatec shows a wealth of aspectual and modal operators, all serving in the establishment of time reference and in the maintenance of temporal coherence in discourse. Every verbal clause in Yucatec obligatorily expresses aspect and mood in two positions: in a preverbal particle, termed Aspect-Mood (AM) marker in Bohnemeyer (1998b), and in a paradigm of verbal suffixes, called status suffixes (following Kaufman 1990:71). The semantics of the preverbally marked categories is different from the semantics of the status suffixes. There are $15 \mathrm{AM}$ categories, as opposed to just five status categories (only four of which occur in main clauses; namely, completive, incompletive, subjunctive, and imperative status). Aside from the imperative, which does not co-occur with any preverbal AM marker, selection of the status category is strictly dependent on selection of the AM category. The set of AM markers contains two prefixes, the perfective AM $j-t /$ - (allomorphs for intransitive and transitive verbs, respectively) and the imperfective AM $k-:^{4}$

$\begin{array}{llll}\text { K-in } & \text { xok-ik } & \text { le } & \text { periyòdiko=o'. } \\ \text { IMPF-A.1.SG read-INC(B.3.SG) } & \text { DET } & \text { newspaper=D2 } \\ \text { 'I (used to) read the paper'. } & & \\ \text { T-in } \quad \text { xok-2j } & \text { le } & \text { periyòodiko=o'. } \\ \text { PRV-A.1.SG read-CMP(B.3.SG) } & \text { DET } & \text { newspaper=D2 } \\ \text { 'I read the paper'. } & & \end{array}$

The imperfective prefix (Example 8) triggers incompletive status marking on the verb, while the perfective prefix (Example 9) triggers completive status marking. In the following analysis, each of the AM markers is treated as representing the combination of the AM marker and the particular status category it governs.

The remaining $13 \mathrm{AM}$ markers are stative predicates and assume the syntactic function of main predicate of the clause (similar to auxiliaries in Indo-European languages). The following examples illustrate the AM markers with (primarily) aspectual meanings; namely, the progressive (Example 10), terminative (Example 11), and prospective (Example 12) AM markers:

$$
\begin{array}{llll}
\text { Táan in } & \text { xok-lk } & \text { le } & \text { periydodiko=0'. } \\
\text { PROG A.1.SG read-INC(B.3.SG) } & \text { DET newspaper=D2 }
\end{array}
$$




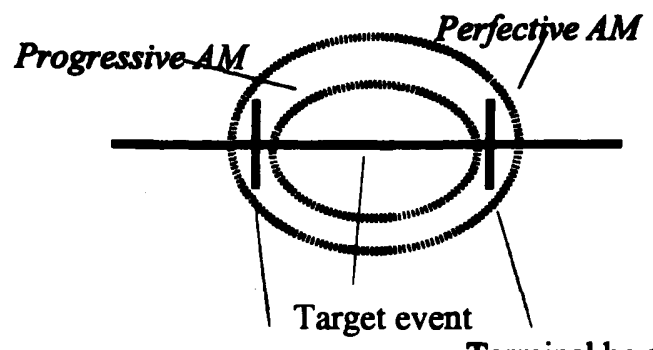

Initial boundary Terminal boundary

Time

Figure 3

Semantics of the perfective and progressive AM markers.

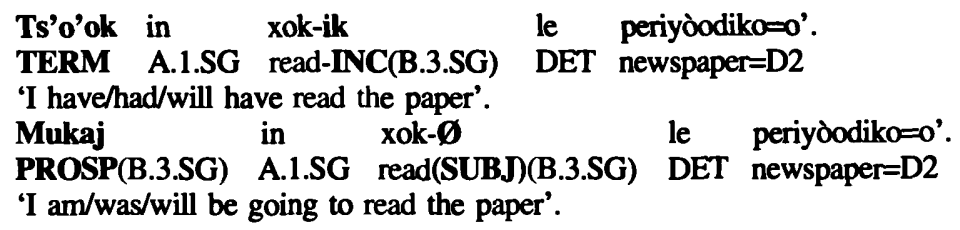

Aside from the AM markers, aspectual meanings are expressed by certain verbal derivations. In addition, just as in English, aspectual notions such as the beginnings and endings of events are referred to by aspectual verbs, also called phase verbs. In the framework laid out in Bohnemeyer (1998b, chpt. 2), aspectual operators are characterized in terms of the part of an event they select for assertion (cf. Chung and Timberlake 1985; Klein 1994; Smith 1991). It is this selected event part that the viewpoint introduced by the aspectual operator "views" or is focused on. Along these lines, the semantics of the perfective and progressive AM markers may be schematically represented as in Figure 3:

The event is represented in Figure 3 with an initial and terminal boundary, a preceding prestate, and a result or post-state caused by the event. The dotted lines delimit the semantic scope of the AM markers. The perfective AM marker includes the boundaries of the event in the scope of assertion (or projection onto the timeline); hence, application of this operator entails completion of the event. In terms of the viewpoint metaphor, this marker indicates an external viewpoint, in which the event is viewed in its totality (cf. Comrie 1976:3). In contrast, the progressive AM marker selects only an internal part of the event for assertion (or, again, projection onto the timeline). Since the terminal boundary is not included in the scope of assertion, application of the progressive AM marker does not entail completion of the event. The event is presented as ongoing - that is, from an internal point of view.

The meaning of the imperfective AM marker is not easily captured in the format of Figure 3, since this operator provides habitual or generic reference, and thus reference to a potentially indefinite number of instances of the event. The remaining aspectual operators of Yucatec are represented in Figure 4: 


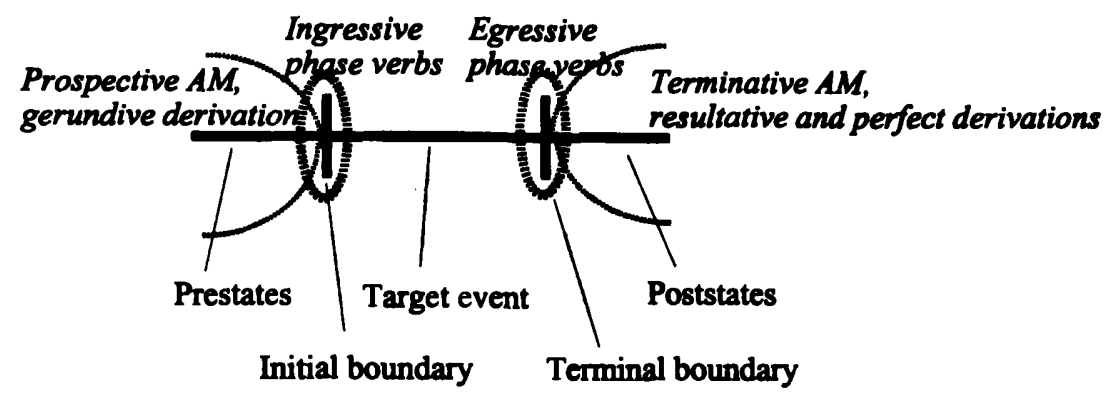

Time

Figure 4

Semantics of further aspectual operators.

The boundaries of an event are referred to using phase verbs. Prestates of an event are selected by application of the prospective AM marker. In addition, prestates of punctual events can also be referred to by use of the progressive AM marker or any of the ingressive phase verbs, and prestates of transitive verbs are accessible through a so-called gerundive derivation. The most general way of referring to any kind of post-state (including the result of a state-change event, but also experiential poststates) is the terminative AM marker and, again, the perfective AM marker (which is in itself indiscriminatory between a perfective reading - presenting the target event inside its boundaries - and a post-state reading). In addition, the resultative (with intransitive verbs, including passivized transitives) and perfect derivations (with transitive verbs) provide post-state reference (however, these are mainly restricted to state-change verbs). ${ }^{5}$

All AM markers are available with virtually all verbs, regardless of their eventstructure semantics (with the exception of some modal verbs that mainly or exclusively occur with the imperfective AM). Moreover, every independent verbal clause obligatorily contains exactly one AM marker. It is thus fair to say that not only are all aspectual viewpoints available with all dynamic events in Yucatec, but at the same time, every independent verbal clause is actually marked for an aspectual viewpoint. Yucatec phase verbs are of an astonishing semantic generality, coming considerably closer to being aspectual operators than do phasal operators in Indo-European languages. In particular, they show fewer restrictions with respect to the event-structure semantics of the embedded verbal core (cf. Bohnemeyer 1998a). ${ }^{6}$

The aspectual operators of Yucatec function in the maintenance of temporal coherence by triggering boundary-to-order implicatures like those illustrated in Examples 2-7 above. The perfective AM marker triggers implicatures from boundedness to nonoverlap, which is interpreted as sequential ordering in combinations of multiple perfective clauses, similar to the implicature illustrated by the English Example 2. The progressive AM marker invites inferences from unboundedness to overlap, resembling the implicature illustrated in Example 3. Post-state operators such as the terminative AM marker and the resultative and perfect derivations trigger inferences of overlap with the post-state of the target event and thereby of precodence of the 
target event. These inferences instantiate the same type of implicature as the one in the English Example 4b. Prestate operators like the prospective AM marker and the genundive derivation invite implicatures of overlap with the prestate of the target event and thereby of precedence with respect to the target event, following the pattern of Example 5b. In addition, ingressive phase verbs are used to implicate nonoverlap with respect to events referred to in preceding discourse and to implicate overlap with respect to events referred to in subsequent discourse, while the egressive operators conversely implicate overlap with respect to events expressed by preceding clauses and nonoverlap with respect to events expressed by subsequent clauses. Boundary-to-order implicatures thus allow speakers of Yucatec to communicate all event-order phenomena in discourse by use of boundary operators. Table 1 summarizes the boundary operators of Yucatec and the boundary-to-order implicatures they trigger. In the following section, the function of these implicatures in creating and maintaining temporal coherence is discussed.

\section{Temporal Coherence in Yucatec Narratives}

The aim of this section is to apply the framework of temporal implicatures sketched above to the analysis of temporal coherence in Yucatec narrative discourse. Due to the lack of expressions of event-order relations in Yucatec, the mapping of events to clauses has to be largely iconic. To achieve this mapping with respect to the networklike event structure of a complex story content, the aspectual operators introduced above are used. This use of aspectual operators in narrative discourse is

Table 1

Yucatec aspectual operators and the temporal inferences they invite.

\begin{tabular}{lll}
\hline \hline Type of Boundary Operator & Yucatec Categories & Implicature Triggered \\
\hline Boundedness operators & Perfective AM marker $t-/ h$ - & Nonoverlap \\
Unboundedness operators & Progressive AM marker táan & Overlap \\
Post-state operators & Terminative AM marker & Overlap with post-state, \\
& $\begin{array}{l}\text { ts'o'ok, resultative (-a'an/ } \\
\text {-Vkbal) and perfect (-mah) }\end{array}$ & i.e., anteriority \\
& derivations
\end{tabular}

Prestate operators

Ingressive operators

Egressive operators
Prospective AM marker mukah, gerundive derivation -bil

Ingressive phase verbs chun, ho'op', kap, etc.

Egressive phase verbs ch'en, p'at, ts'o'ok, xúul, $x u n$, etc.
Overlap with prestate, i.e., posteriority

Nonoverlap with respect events in preceding discourse, overlap with respect to events in following discourse

Overlap with respect to events in preceding discourse, nonoverlap with respect to events in following discourse 
discussed here with respect to a folktale I recorded in the summer of 1999, entitled Bix kajnal le nukuch máako'ob úuch wayo', 'How the Old Folks Used to Live Here in the Old Days' (henceforth Kajnal). This is, despite the title, a demon story that relates how a woman saves her life and the lives of her children from the persecution of a demon who has already devoured her husband. The story is told against the background of life on isolated ranchos in the jungle. Ranchos are remote outlier settlements of usually just one family, which formed the predominant settlement pattern in the Southeast of the Yucatan peninsula before the arrival of paved roads in the 1940s. The story was told by VEC, a 72-year-old male near-monolingual, in the village of Yaxley (municipal district of Felipe Carrillo Puerto) in Quintana Roo, Mexico, and transcribed and coded by the author in consultation with EMB, a 45-year-old male bilingual. The recording is about twenty-three minutes long.

The story was selected for two reasons. First, it shows a relatively complex temporal structure. The story unfolds in three subsequent locations: the husband's milpa (cornfield), where he is attacked and eaten by the demon; the family's rancho, where the demon intrudes as an imposter, having assumed the shape of the man he has eaten; and a hiding place in the jungle to which the woman flees at night, after she has hidden her older children, taking her youngest child with her. It is narrated from the perspective of five different (groups of) characters: the man (who sees the demon coming for him, but cannot escape), his son (who is the first to realize the true identity of the demon posing as his father), the woman (who initially cooperates, preparing a bath for the demon and having intercourse with him, until he falls asleep and she can sneak out), the demon (trying to overpower the woman after he has tracked her down where she is hiding in the top of a tree), and a group of travelers who, attracted by the woman's cries for help, eventually kill the demon. The perspective of a character is introduced and maintained-apart, of course, from speech reproduction--mainly by the experiencer arguments of verbs of perception, cognition, or emotional involvement. On several occasions, background information is presented in order to explain events that happen in the foreground storyline, and there is even a flashback spanning across several clauses, a device rather rarely found in Mayan narratives. On a purely temporal plain, complexity manifests itself in terms of the topological relations of sequence and (partial or complete) overlap. In this respect, Kajnal is fairly simple. There are, for example, no multiple simultaneous storylines developing in parallel. The complexity addressed in this section is instead a matter of the presentation of events - in other words, of the interaction of event order and rhetorical structure.

The second reason for selecting Kajnal for analysis is that the story is rich in the aspectual and modal operators it features. No fewer than 11 of the 15 AM markers of Yucatec are instantiated in the text, and there are tokens of all three aspectual derivations (resultative, perfect, gerundive) and of all major connective constructions expressing aspectual or modal meanings. Tables 2 and 3 present the numbers of tokens of each of these operators. The second column represents the tokens of the aspectual and modal operators in the first 177 utterance units (uus) which lay out the general background of the story, describing the conditions of life on a rancho in the old days. ${ }^{7}$ This part of the text belongs to a different genre; it is descriptive rather than narrative. Consequently, it features aspectual marking rather different from what is found in the remainder of the text: The predominant AM marker in the first 177 uus is the imperfective AM, which signals habitual or generic reference, whereas the wWW.anthrosource.net 
predominant AM marker in the remaining 444 uus is the perfective AM. These 444 uus are further broken down in Table 2 into reported speech (i.e., character utterances) and the remaining main narrative text. Again, embedded character speech belongs to a different type of discourse (conversational or dialogical rather than monologic) and accordingly shows different patterns of AM marking. ${ }^{8}$ The rightmost column of Table 2 presents the total figures for the Kajnal text. Note that stative clauses (i.e., clauses headed by nonverbal predicates) are not marked for AM. As Table 2 shows, stative clauses are much more frequent in descriptive than in narrative discourse (43 percent of the uus in the descriptive part of Kajnal are stative clauses, as opposed to just 16 percent in the main narrative text).

"Other AM" markers include one token each of the proximate future AM ta'itak and the recent past $\mathrm{AM}$ sáam, two tokens each of the necessitive $\mathrm{AM} k^{\prime} a^{\prime} a a^{\prime} a a^{\prime}$ and the assurative $\mathrm{AM} h e^{\prime} . . .=e^{\prime}$, five tokens of the obligative AM yan (all of the aforementioned occurring in the main narrative part, and there mostly in character speech), and nine tokens of the desiderative AM táak (of which one occurs in the narrative part and eight in the introductory descriptive part). Focus constructions, certain subordinate clauses, and negated clauses show distinct patterns of AM marking. In these constructions, fewer categories are distinguished than in unfocused affirmative main clauses, and they are partly marked in different ways (see Bohnemeyer 1998b:188-203). In Table 2, these constructions appear under the rubric of "other constructions."

The connectives listed in Table 3 convey aspectual and modal meanings as well. Some additional examples are discussed briefly below; for details, the reader is referred to Bohnemeyer (1998a, 1998b:485-503).

Table 2

Aspectual operators in the Kajnal text.

\begin{tabular}{|c|c|c|c|c|}
\hline Category/construction & $\begin{array}{l}\text { Descriptive text } \\
\text { (first } 177 \text { uus) }\end{array}$ & $\begin{array}{l}\text { Reported speech } \\
\text { (character } \\
\text { utterances, } \\
126 \text { uus) }\end{array}$ & $\begin{array}{l}\text { Main narrative } \\
\text { text (318 uus) }\end{array}$ & $\begin{array}{c}\text { Total } \\
\text { (621 uus) }\end{array}$ \\
\hline Stative clauses & $76(43 \%)$ & $28(22 \%)$ & $50(16 \%)$ & $154(25 \%)$ \\
\hline A Imperfective & $46(26 \%)$ & $6(5 \%)$ & $34(11 \%)$ & $86(14 \%)$ \\
\hline Perfective & $2(1 \%)$ & $4(3 \%)$ & $113(36 \%)$ & $119(19 \%)$ \\
\hline Progressive & $3(2 \%)$ & $3(2 \%)$ & $16(5 \%)$ & $22(4 \%)$ \\
\hline Terminative & $2(1 \%)$ & $4(3 \%)$ & $7(2 \%)$ & $13(2 \%)$ \\
\hline e Prospective & $2(1 \%)$ & $\%)$ & $0(0 \%)$ & $3(0 \%)$ \\
\hline Other AM & $8(5 \%)$ & $7(6 \%)$ & $5(2 \%)$ & $20(3 \%)$ \\
\hline Derivations & $5(3 \%)$ & $1(1 \%)$ & $11(3 \%)$ & $17(3 \%)$ \\
\hline Other constructions & $33(19 \%)$ & $72(57 \%)$ & $82(26 \%)$ & $187(30 \%)$ \\
\hline Total & 177 (100\%) & $126(100 \%)$ & $318(100 \%)$ & $621(100 \%)$ \\
\hline
\end{tabular}


Table 3

Aspectual connectives in the Kajnal text.

\begin{tabular}{lcccc}
\hline \hline Connective & $\begin{array}{c}\text { Descriptive text } \\
\text { (first 177 uus) }\end{array}$ & $\begin{array}{c}\text { Reported speech } \\
\text { (character } \\
\text { utterances, 126 uus) }\end{array}$ & $\begin{array}{c}\text { Main narrative } \\
\text { text (318 uus) }\end{array}$ & $\begin{array}{c}\text { Total } \\
\text { (621 uus) }\end{array}$ \\
\hline$k a ́ a+$ PRV & $0(0 \%)$ & $1(20 \%)$ & $99(88 \%)$ & $100(76 \%)$ \\
$k a p^{\prime}+$ INC & $1(8 \%)$ & $0(0 \%)$ & $9(8 \%)$ & $10(8 \%)$ \\
$k e ́ e n+$ SUBJ & $12(92 \%)$ & $4(80 \%)$ & $5(4 \%)$ & $21(16 \%)$ \\
Total & $13(100 \%)$ & $5(100 \%)$ & $113(100 \%)$ & $131(100 \%)$ \\
\hline
\end{tabular}

While the connective káa co-occurs with the perfective AM $t$-/h-, the connectives kéen and kap' occur without AM markers, combining with bare verbal cores inflected for subjunctive and incompletive status respectively. Consequently, clauses headed by káa are also counted for perfective AM in Table 2, while clauses headed by kéen or kap' fit into the category of "other constructions." [Kap' V-INC] has grammaticalized out of [káa j jo'op' V-INC] káa PRV begin(B.3.SG) V-INC 'It started to $\mathrm{V}^{\prime}$ and signals imperfectivity in connected speech, in parallel to káa, as discussed below (cf. Bohnemeyer 1998b:490-492).

The remainder of the discussion is focused on the main narrative text of Kajnal. The basic clause type used for narrating main storyline events in Yucatec is the dynamic clause marked for perfective AM and introduced by the connective káa. As is apparent from Table 2, this construction accounts for 31 percent of all uus in the main narrative text of Kajnal, and it occurs about as frequently as all other AM marking constructions together in the main narrative text (including the perfective AM marker not accompanied by káa). In contrast, this construction occurs only once in character speech, and not at all in the descriptive part of Kajnal. Káa occurs exclusively with the perfective $\mathrm{AM}$ and serves to disambiguate its meaning, which covers both a bounded reading (as in The car broke) and a post-state reading (as in The car is broken). The connective káa forces the bounded reading, which may indicate sequential order, as in Example 13a 'Pedro wrote a letter and smoked a cigarette', but this is no more than an implicature.

(13) a. Pedro=e' káa t-u ts'íb-t-aj jun-p'éel Pedro=TOP káa PRV-A.3 write-APP-CMP(B.3.SG) one-CL.IN kdarta=e', ḱa t-u ts'u'uts'-aj jun-p'Gel chamal. letter=TOP kfa PRV-A.3 suck-CMP(B.3.SG) one-CL.IN cigarette 'Pedro, (when) he wrote a letter, he smoked a cigarette.' (Elicited; default interpretation: sequential)

$\begin{array}{llll}\text { b. Káa t-u } & \text { ts' fib-t-aj } & \text { jun-p'́el kàarta Pedro=e', } \\ \text { káa PRV-A.3 } & \text { write-APP-CMP(B.3.SG) one-CL.IN letter Pedro=TOP }\end{array}$ Juán=e' káa t-u ts'u'uts'-aj jun-p'cel chamal. Juán=TOP káa PRV-A.3 suck-CMP(B.3.SG) one-CL.IN cigarette '(When) Pedro wrote a letter, Juán smoked a cigarette. ' (Elicited; default interpretation for four out of five consultants: simultaneous) 
In Example 13b, which differs from 13a in that the two clauses have different actor arguments ('Pedro wrote a letter, and Juan smoked a cigarette'), it is still understood that both events are bounded or completed, but this time, it is inferred that the two events occurred simultaneously. In 13b, káa might be analyzed as a generic temporal connective such as when or then (i.e., a connective that does not specify a particular event order, but only indicates that the time of the main clause is somehow determined with respect to the time of the subordinate clause). 13b would then read something like 'When Pedro wrote the letter, then Juan smoked a cigarette'. This analysis is, however, excluded by $13 \mathrm{a}$, in which the reference time of the second clause is shifted rather than determined with respect to that of the first clause.

The first occurrence of a káa-clause in Kajnal in fact marks the very beginning of the narrative storyline:

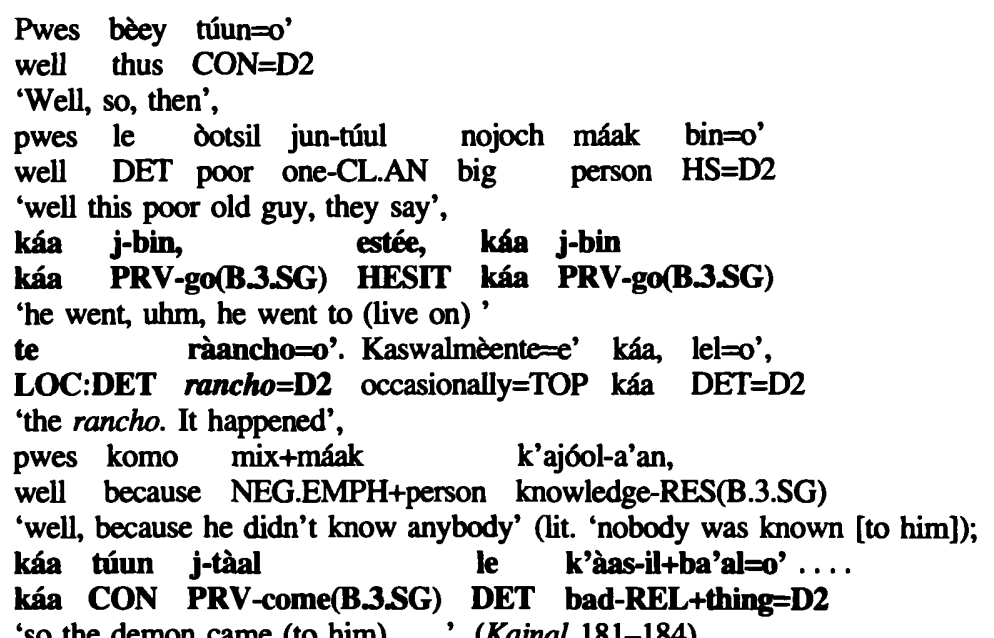

'so the demon came (to him) ...' '. (Kajnal 181-184)

The first káa-clause (preceded by the topicalized NP le òotsil juntúul nojoch máak 'this poor old guy') narrates the man's decision to live on a rancho. The second káaclause refers to the appearance of the demon. This clause is preceded by a topicalized stative clause komo mixmáak k'ajóola'an 'because he didn't know anybody', which presents background information for the purpose of explaining why the demon chose this man as his prey. ${ }^{10}$ The state of the man's not knowing anybody is interpreted to overlap with the event of the demon's appearing, because states are by default interpreted as unbounded. Strictly speaking, the state of knowing somebody is presented in Example 14 as the post-state of getting to know somebody, through the use of the resultative form in - $a^{\prime}$ an of the applicative verb $k$ 'ajool-t knowledgeAPP 'get to know' (the applicative marker - $t$ is elided in the formation of the secondgeneration resultative derivation $k^{\prime} a j \delta o l-a$ 'an). So the clause most literally translates as something like 'because nobody had come to be known (to/by him)'. However, for present purposes, the backgrounded event of getting to know somebody can be neglected, as it does not form part of the story.

The notion that the main storyline in narratives is presented as a sequence of bounded events (i.e., events viewed as bounded, hence perfectively) in the foreground, and that this foreground sequence is interpreted to be iconically matched by the order 
of mention, whereas background information tends to be nonsequential and does not participate in iconic interpretation, is well known from both typological studies and studies of Indo-European languages (Hopper 1979; Labov 1972; Labov and Waletzky 1967; Thelin 1990; Weinreich 1964). This generalization would certainly seem to be valid as a tendency for Yucatec as well. It does, however, seem to require some qualification (and this in turn may hold not just for Yucatec). First of all, the domain of iconic interpretation has to be constrained. It would seem impossible simply from a processing point of view to expect iconic sequentializing of an entire oral narrative of the size of Kajnal, given that such sequentializing would have to be planned in advance. I submit the hypothesis that iconic interpretation of narrative sequences applies within the confines of a unit of discourse organization that also manifests itself in other phenomena, such as intonation and topicality of referents, and that corresponds to an underlying planning unit of discourse production and comprehension. I claim that in Yucatec, this unit can be identified as a narrative paragraph. This proposal will of course have to be validated with respect to a much larger database (and I do not expect it to be universally true!). For now, I have to confine myself to an example. The passage in Example 14 continues with the demon approaching, having assumed human shape (man-eating demons or monsters that shift between animal and human shapes are a common topic of Mayan folk narratives; see Edmonson and Bricker 1985:56; Stross 1978). Then, on the account presented here, there is a paragraph boundary, after which Example 15 follows:

$$
\begin{aligned}
& \text { Le dotsil máak=o', káa j-bin te'el ich } \\
& \text { DET poor man=D2 káa PRV-go(B.3.SG) there in } \\
& \text { 'The poor man, he went (out) there to' } \\
& \text { le kòol=o'. Ti', bin, yàan te ka'anal=o', }
\end{aligned}
$$$$
\text { DET clearlATP=D2 LOC HS EXIST(B.3.SG) LOC:DET high=D2 }
$$$$
\text { 'the milpa ('comfield,' lit. 'clearance'). There he was, they say, up high' (i.e., }
$$$$
\text { in a tree), }
$$$$
\text { chéen káa t il-aj }
$$$$
\text { only káa PRV:A.1.PL see-CMP(B.3.SG) }
$$$$
\text { '(and) he saw' }
$$$$
\text { u tiip'-il, bin, le ba'al=o'; túun tàal. }
$$$$
\text { A.3 appear-INC HS DET thing=D2 PROG:A.3 come(INC) }
$$$$
\text { 'the thing (i.e., the demon) appear, they say; it was coming'. (Kajnal 187-190) }
$$

The events of the passage in Example 15 certainly cannot be considered to follow the events in 14 in strictly sequential order, because the approach of the demon was already referred to at the end of 14 . Also, the man's decision to move out to live with his family on a rancho, referred to by the first káa-clause in 14, is located on a different time scale, or a different level of event granularity, from the time scale and event granularity of the man's leaving home to work on his milpa as reported in the first $k a$ a-clause of 15 (it may be easily assumed that several years passed in between the two events). The question is now: Is there independent evidence that suggests a paragraph boundary preceding 15? I would argue that such evidence can be found both in the intonation (there is a relatively long pause preceding 15; before this pause, pitch reaches an absolute low, and following the pause, pitch rises again) and in the fact that reference to the man is taken up at the beginning of 15 neither by a simple pronoun nor even by a clause-internal noun phrase, but rather by the topicalized noun phrase le dotsil máako' '(as for) that old man'. A topicalized full noun www.anthros urce.net 
phrase resuming an already introduced referent violates general principles of argument realization (or "preferred argument structure"; cf. Du Bois 1987). This reflects a disruption of the narrative production process and may well be employed actually to signal a boundary in the discourse organization. Of course, such resumptive topics are not necessary in the introduction of paragraphs; their use to mark paragraph boundaries is entirely optional. Below, I discuss a paragraph boundary that isolates a paragraph containing an actual flashback. However, within the confines of the paragraph unit as introduced above, there is no violation of iconic discourse structure in the entire Kajnal text, and I am not aware of such a violation in any Yucatec narrative.

The second respect in which it is necessary to refine the principle that information in the narrative foreground typically represents sequential events in iconic order is that events pertaining to the main storyline may be represented as overlapping as well. An example is the last two lines in Example 15: Naturally, the event of the demon's approaching overlaps with the event of the man's seeing it approach; both events are equally important for the advancement of the story, and neither can be considered to be backgrounded. The overlap is represented by marking the event of the demon's approaching as unbounded, using the progressive AM marker, which shifts the aspectual viewpoint to the inside of the event-that is, it excludes the event's boundaries from assertion. This triggers an implicature from unboundedness to overlap of the same type that was illustrated above with the English example 3b. That this overlap is really only implicated but not entailed by the use of the progressive $\mathrm{AM}$ can be shown by examples such as 16 :

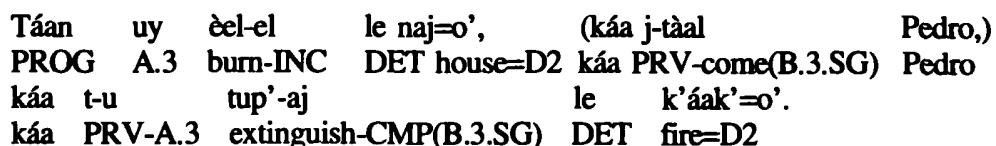

'The house was on fire (lit. 'burning'), ((when) Pedro came) and extinguished the fire'. (Elicited)

The second clause indeed refers to an event in overlap with the house's being on fire, but this clause can be omitted, and regardless of whether it is or not, the third clause would have to be interpreted as referring to an event simultaneous with the house's being on fire, were it not the case that world knowledge rules out this inference. ${ }^{11}$

The third caveat to the principle of iconic sequencing in narrative foreground is that events presented as background information do not necessarily overlap with the events presented in foreground (Example 17):

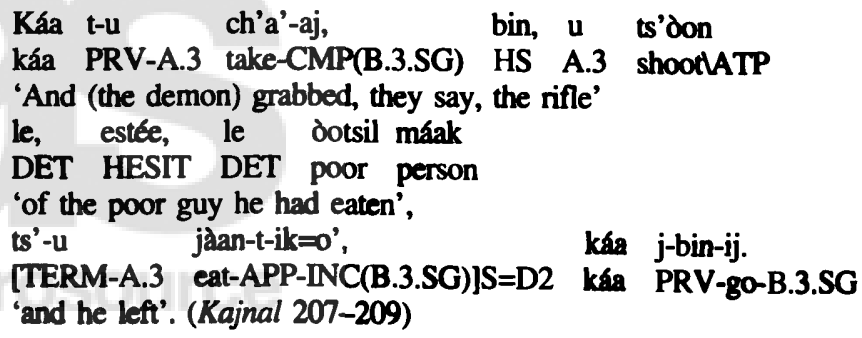


The passage quoted in Example 17 relates events that take place after the demon has devoured its victim. The second line of 17 contains a relative clause, $t s$ ' $u$ jadantik 'he has/had eaten him', that refers back to this episode. By virtue of being subordinate, the relative clause is an appropriate means of conveying background information (Reinhart 1984; Thompson 1987; Tomlin 1985). In this case, the background information serves to identify the owner of the rifle the demon takes with him as the man the demon ate earlier.

The question arises of how to reconcile this backward reference to an event that happened before the event to which the preceding main clause refers (the demon's grabbing the rifle) with the constraint of iconic discourse structure within paragraph boundaries. This is achieved by using the terminative AM marker, which shifts the aspectual viewpoint to a post-state caused by the event (cf. Figure 4). This post-state is not a time interval following the event, but rather an eventuality in its own right. Evidence for the aspectual behavior of the terminative AM marker comes from the fact that it cannot be applied to an event with respect to a time at which its post-state does not obtain any longer and, more importantly, from the incompatibility the terminative AM marker displays vis-à-vis event-time adverbials (Bohnemeyer 1998b:350-360). This post-state is by default interpreted unboundedly (i.e., imperfectively), like all states. Hence it is inferred in 17 that the post-state of eating the man (i.e., the state of the demon's having eaten the man) overlaps with the main clause event of grabbing the man's rifle. And from this it is further inferred that the man-eating event preceded the rifle-grabbing event. But in semantic terms, what is coded is only the post-state of the man-eating event, which is understood to overlap with the rifle-grabbing event; hence iconicity is preserved. The entire computation of time reference in 17 is schematically depicted in Figure 5. The inference processes represented in Figure 5 together form an instance of the implicature from post-state aspectual modification to anterior event order that was illustrated above with the English Example $4 .^{12}$ In much the same way, a prestate aspect or a modal operator may be used to anticipate events in the relative future of a main storyline event, instantiating an implicature of the type illustrated in Figure 5. There is no example of this in Kajnal, but see Bohnemeyer (1998b:360-377) for some illustration.

Example 17 has illustrated how events outside the main storyline that precede or follow the main narrative events can be adapted to the iconic discourse structure by the application of operators that shift the aspectual viewpoint. The final question to be addressed now is: How far can this strategy of iconicity preservation by viewpoint

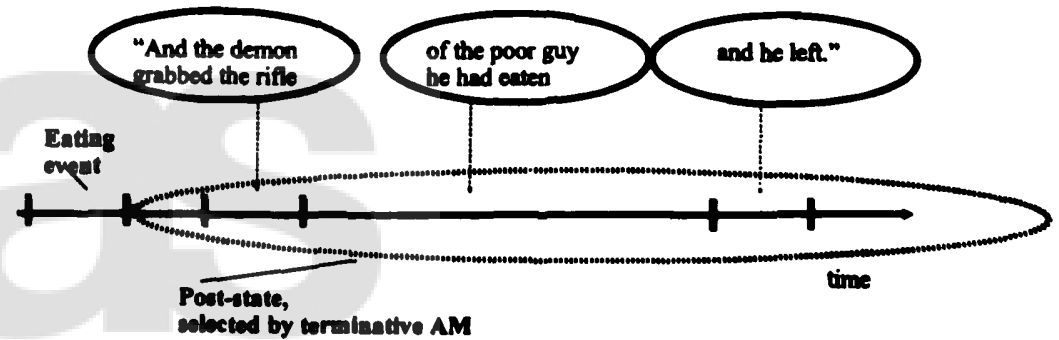


shifts be stretched? In Example 17, it is only a single relative clause that refers to an event preceding the main clause event, and this relative clause clearly serves a nonnarrative function: It simply helps restrict the reference of a noun phrase. (Intonation identifies the relative clause in Example 17 as restrictive, although the purely linguistic context would allow for both a restrictive and an appositive interpretation.) If, however, the main storyline narration is interrupted to refer to an entire episode preceding the events in the main storyline - probably, but not necessarily, as background informationthen this constitutes what may be called a flashback. Such flashbacks are fairly rare in Yucatec narratives; it seems plausible that this is motivated by the lack of expressions of event order. ${ }^{13} \mathrm{Kajnal}$, however, does contain one flashback, of a sort. The beginning of this flashback is given in Example 18. The story has advanced now to the point at which the woman has run off from the sleeping demon. The demon has awakened and started to chase the woman, shouting out for her. On hearing the demon, the woman has decided to climb a tree. Her only weapon is a weaving sword that she will use now instead of a machete. In order to explain this, the narrator goes into a flashback.
$Y=$ étel,
bin, jun-p'éel jalab+te'
A.3=with(B.3.SG)
HS one-CL.IN (plant)+tree
'It was, they say, with a jalabte' (a weaving sword made of the wood of the jalabte' tree)' (i.e., that she had fled from the demon),
ikil u, estée u sakal; le máaskab=o',
INSTR A.3 HESIT A.3 weave DET machet e(B.3.SG)=D2
'with which she used to weave, (this was) the machete',
u máaskab bè $=0$ ',
A.3 machete(B.3.SG) thus=D2
'(this was) her machete thus',
$y=$ =étel, bin; t-u ch'a'-aj bèey=o'
A.3=with(B.3.SG) HS PRV-A.3 take-CMP(B.3.SG) thus=D2
'with this it was (that she had run), they say; she had grabbed thus'
le jalab+te' bèey $=0$ ' ikil u sakal $=0$ ' bèey $=a$ '.
DET (plant)+tree thus=D2 [INSTR A.3 weave(INC) $=$ D2 thus $=$ D1]s 'the jalabte' thus, with which she used to weave like this'.
U jéen-t-aj-maj,
bin,
A.3 sling-across.shoulder-APP-CMP-PERF(B.3.SG) HS
'She had it slung across her shoulder, they say',
k-u
bin.
[IMPF-A.3 go(INC)]s
'on leaving' (lit. 'she leaves'). (Kajnal 391-395)

Example 18 is again separated from the preceding text by a relatively salient pause, after which a new intonation contour starts. The first clause introduces the theme of the following text segment, the jalabte' 'weaving sword', with a full noun phrase. Intonation and the topicality of participants therefore suggest that Example 18 is the beginning of a new paragraph. It starts by narrating that the woman had her jalabte' with her instead of a machete. This is a state that is interpreted to obtain at the time to which the story has advanced at this point-in other words, it is interpreted to overlap with the woman's climbing the tree while being persecuted by the demon. The following four clauses refer back to events that happened earlier, when the woman sneaked out of her house. Significantly, none of the clauses features the kba-plusperfective-AM construction that is typically used for relating main storyline events. 
The first clause in boldface is formed with the perfective AM marker alone. As mentioned above, this marker is polysemous, embracing a perfective reading (referring to the event including its boundaries) and a post-state reading. Káa resolves this ambiguity by excluding a post-state interpretation. In the context of 18 , however, it is precisely the post-state reading that is understood to obtain. The clause serves to assert not the event of grabbing the jalabte', but the state of having grabbed it, which is interpreted to overlap with the time to which the story has advanced, in much the same way as in 17 above, the post-state of the demon's devouring the man is interpreted to overlap with the time at which the demon picks up the man's rifle.

The sentence that contains the clause formed with the perfective AM marker also contains a relative clause introduced by the instrumental preposition ikil. Like many other types of subordinate clauses, this relative clause does not contain an AM marker (to this extent it may be compared to nonfinite clauses in Indo-European languages). The verb appears in incompletive status, which in isolation expresses unboundedness, not unlike the English gerund in -ing (cf. Bohnemeyer 1998b:294-300). In this case, the weaving activity referred to by the clause has a habitual interpretation (which in main clauses would be expressed using the imperfective AM marker). Customary use in weaving, understood to overlap with the time at which it is converted into a machete, is attributed to the jalabte' to explain its availability to the woman.

The following two clauses show a construction in which a clause marked for imperfective AM is subordinate in antitopic position (Lambrecht 1994) to a main clause formed by a verb stem that appears in the derived perfect form. As mentioned above, the perfect and resultative derivations both serve to express post-states. What the main clause in the penultimate line of Example 18 asserts is the post-state of the woman's slinging the jalabte' across her shoulder, or in other words, the state of having slung it across her shoulder. The antitopic clause serves to fix the time for which this post-state is asserted: the moment that the woman leaves her house. As is argued in Bohnemeyer (1998b:330-338), the more frequent uses of the imperfective AM marker in expressing habitual or generic readings are but special instances of a more general "inactual" meaning. In this case, the function of the imperfective-AM clause is to take up an event that was, unlike the woman's grabbing her jalabte', narrated before (namely, her leaving the house), without asserting it again. The entire construction reads something like 'The woman had slung (the jalabte') across her shoulder, (on) leaving'.

None of the events that form part of the flashback are asserted within their boundaries, unlike perfective main storyline events. Accordingly, none of the events is referred to using a kaa-plus-perfective-AM clause. The paragraph continues by providing generic information about how instruments such as weaving swords, since they are conceived of as magical agents, possess supematural powers, which explains why the woman would be able to use the jalabte' instead of a machete as a weapon (when the demon reaches the tree and attempts to climb after the woman, she hacks off his claws with the jalabte'). Having provided the information about the magical powers of the jalabte', the narrator introduces another paragraph break, after which he resumes the main storyline, using kba-clauses once again. Thus, Example 18 illustrates how even in short flashbacks, aspectual viewpoint shifts (and modal quali- 


\section{Conclusion}

Because of the lack of event-order relators such as tenses and temporal connectives the coding of events in Yucatec discourse is subject to a strict iconicity constraint. It has been shown in this article how aspectual operators that introduce viewpoint shifts are used to reconcile this principle of iconicity preservation with the requirements of narrative discourse, in which events need to be presented in an order that does not always match the linear sequence of clauses. Furthermore, a hypothesis has been advanced (and initial support has been provided for it) to the effect that the iconicity constraint in Yucatec holds only within paragraph boundaries, in such a way that the paragraph is defined as a unit of cognitive processing that has independent structural correlates.

\section{Notes}

Acknowledgments. A version of this article was presented at the symposium "Telling Time: Temporal Coherence in Narrative" at the 98th annual meeting of the American Anthropological Association in Chicago, November 17-21, 1999. I would like to thank the organizer and the participants of the symposium, as well as Penny Brown, Michael Dunn, Anna Margetts, Loretta O'Connor, Mary Swift, Angela Terrill, and three anonymous reviewers for comments and helpful suggestions. The field research this article is based on was fully supported by the Max Planck Society.

1. Normally, now marks a time that overlaps with coding time, as in I can't talk to you just now, but the coding time of this particle in Example 1 cannot be the same as the coding time of the past-tense forms. It appears to be shifted from the perspective of author and readers to the perspective of the characters in the narrative, an instance of what is known as transposed deixis (Bühler 1934).

2. Beside the modes of time reference illustrated so far-namely deictic reference, in which the reference point is coding time, and anaphoric reference, in which the reference point is given in discourse-there is a third mode, calendrical reference, which anchors events or time intervals with respect to some calendrical time scale. Calendrical time reference is illustrated by adverbials such as on Monday, at 3 p.m., and in 52 B.C. However, the focus of attention in this article is on expressions of the relative order of events in narratives-that is, on anaphoric time reference.

3. Event-order inferences from aspectual information have been discussed in the formal semantics literature on so-called temporal anaphora phenomena. Key contributions to this line of research include Bach 1981, Dowty 1986, Hinrichs 1986, Kamp and Rohrer 1983, and Partee 1973 and 1984.

4. The orthography applied in this article is one codified in 1984 by a number of national and local institutions (cf. Ayres and Pfeiler 1997:91-92). The representation of lexical elements is morphemic rather than morphophonemic. In the interlinear morpheme glosses, the following conventions are used: '-' for affixes; ' $=$ ' for clitics; ' + ' for compounding; 'l' for subsegmental realization or infixation. Abbreviations in the interlinear glosses include the following: 1-first person; 3-third person; A-set-A ("ergative"/possessor) clitics; AN-animate (numeral classifier); APP-applicative derivation; ATP-antipassive derivation; B-set-B ("absolutive") suffixes; $\mathrm{CL}$-numeral classifier; CMP-completive status; $\mathrm{CON}$-connective particle; D1-proximal-deictic particle; D2-distal-deictic/anaphoric particle; DET-determiner; EMPH-emphatic (negation); EXIST-existential/locative/possessive predicate; HESIT-hesitation; HS-hearsay (evidential particle); IMPF-imperfoctive aspect; IN-inanimate (numeral classifier); INC-incompletive status; INSTR-instrumental subondinator; LOCgeneric preposition; NEG-negation particle; PERF-perfect derivation; PL-plural; PROG- 
progressive aspect; PROSP-prospective aspect; PRV-perfective aspect; REL-relational derivation (nouns); RES-resultative derivation; SG-singular; TERM-terminative aspect; SUBJ-subjunctive status; TOP-topic marker.

5. The gerundive (-bil), resultative (- $\left.a^{\prime} a n,-V k b a l\right)$, and perfect (-maj) forms constitute derived stative predicates. Unlike verbs, these do not inflect for status. Therefore, these forms should not be treated on a par with the AM markers. Example 14 shows resultative $-a$ 'an and Example 18 shows perfect-maj.

6. Strikingly, all ingressive phase verbs (e.g., chun, jo'op', and kaj, all roughly 'to start') and one egressive verb ( $t s^{\prime} o$ ' $o k$ 'end') are compatible with punctual embedded verbs. It is in no way peculiar in Yucatec to say Káa j jo'op'/ts'o'ok in wahale' 'I started/finished waking up'. The phase verbs may be used in such contexts to signal pre- or post-state reference (Káa jjo'op' in wahale' may be used to refer to the prestate of waking up, as in 'I was going to wake up', and Káa jts'o'ok in wahale' may be used to refer to the post-state of waking up, as in 'I had woken up'). Ts' $o$ ' $o k$ is also remarkable in that it combines with both telic and atelic predicates. In English, complete, end, and finish entail achievement of some inherent endpoint (e.g., realization of a result state) and combine only with telic predicates, whereas the egressive phase verbs that are compatible with atelic predicates, such as stop and quit, do not entail event realization when combined with telic predicates and instead implicate interruption or abandonment (cf. Freed 1979). In contrast, $t s^{\prime} o$ 'ok can denote the terminal boundary of any event, entailing realization of an inherent endpoint if such an endpoint is part of the embedded predicate's meaning, but simply imposing termination if no endpoint is defined by the predicate. In discourse, the semantic generality of $t s^{\prime} o$ ' $o k$ is exploited to generate boundary-to-order implicatures from completion of one event with respect to another event to sequential ordering of the two events (cf. Bohnemeyer 1998a, 1998b:209-215, 429-431). Ts'o'ok is used as a sequentializer in particular in procedural texts, but also in narratives (it occurs six times in this function in the folktale analyzed in this article).

7. For the purposes of coding and statistics, the Kajnal text was broken down exhaustively into 621 successive utterance units (uus). This is a technical unit that comprises no more than one independent or subordinate clause plus all material adjacent to it that does not itself form a constituent of a clause (e.g., topicalized noun phrases, but also interjections such as Wow!', vocatives such as Young man (, ...)!, etc.), but maximally one conversational turn. If an entire turn in reported speech consisted of nothing more than an interjection, exclamation, vocative, or the like, this was counted as an utterance unit as well. There are 22 of these nonclausal uus in the text, so the text contains 599 clauses plus adjacent material. However, reported speech (utterances by the narrative's characters) is usually accompanied by an utterance marker that may be a full clause (e.g., $T$-y=a'al-aj PRF-A.3=say-CMP(B.3.SG) '(S)he said it'), but may also be merely a particle ( $k i$ 'said (s)he'). These utterance markers were counted in any case as separate uus, because they anchor reported speech in the main storyline and therefore can be assigned a distinct temporal location within the story time. There are 52 such utterance markers in the Kajnal text.

8. Burns (1983:19-24) emphasizes the dialogical nature of Yucatec narratives. But this is an interactiveness of a different kind from that found in conversations: The roles of narrator and audience are clearly distinct and do not change during the narration. In any case, the relevant sense of connectedess that accounts for the difference in the distribution of aspect markers across the two genres is not so much the uninterrupted production of multiple sentences by one speaker. Rather, it is the presentation of events as parts of a larger story.

9. "Other constructions" in the descriptive part include 15 focus constructions without AM markers (among them one in which the extrafocal part is introduced by the irrealis subordinator kén); 11 topicalized clauses with the irrealis subordinator keen, which governs subjunctive status (cf. Bohnemeyer 1998b:492-497); two other subordinate clauses without AM markers; and one ingressive clause with kap' plus incompletive. The remaining four uus consist of www.anthrosource.net 
exclamations and the like. "Other constructions" in reported speech include 19 imperative, six exhortative, and three presentative clauses; eight focus constructions without AM markers (among them four containing the irrealis subordinator kéen); and 18 subordinate clauses without AM markers. The remaining 18 uus consist of exclamations and the like. "Other constructions" in the main narrative include 52 tokens of the quotative particle $k i$ 'said (s)he' and other utterance markers, nine ingressive clauses with kap' plus incompletive, five clauses headed by the irrealis subordinator keen, six other subordinate clauses without AM markers, and six focus constructions without AM markers. The remaining four uus consist of exclamations and the like.

10. Various types of subordinate clauses that translate adverbial clauses in Indo-European languages are not embedded, but realized in a topic or antitopic position in Yucatec (cf. Bohnemeyer 1998c; see also Example 18). The dedicated topic marker $=e$ ' that follows the adverb kaswalmènte 'occasionally' in Example 14 is suppressed by the indexical particle $=a$ ' (proximal) or $=o^{\prime}$ (distal or anaphoric) whenever the topicalized phrase or clause contains a definite noun phrase or a deictic stem.

11. The phenomena of causality or paraphrase relations overriding the default inferences otherwise drawn from aspectual information have received considerable attention in the study of temporal coherence in Indo-European (Lascarides 1992; Lascarides and Asher 1993).

12. However, the English pluperfect employed in Example 4 has properties that distinguish it rather markedly from the terminative AM marker of Yucatec. Not only does the pluperfect have a deictic tense component, but it also behaves differently with respect to timelocational adverbials. Whereas the Yucatec terminative AM marker can be combined only with adverbials that qualify the time for which the post-state is asserted, the English pluperfect is compatible with both assertion-time and event-time adverbials (hence the ambiguity of utterances such as She had read the article in the afternoon). This gives room for an analysis of the nondeictic component of the pluperfect in terms of a relative tense (cf. Comrie 1985:56-64) rather than an aspectual operator, along the lines of Reichenbach's (1947) proposal. For an aspectual analysis of the English perfect tenses, see Klein 1992.

13. One reviewer suggests that reported speech may be used in narratives to realize a pragmatic equivalent of flashbacks. This idea definitely deserves further study.

\section{References Cited}

Ayres, Glenn, and Barbara Pfeiler

1997 Los verbos Mayas: La conjugación en el Maya Yucateco moderno (Mayan verbs: Conjugation in modern Yucatec Maya). Mérida, Yucatan: Ediciones de la Universidad Autónoma de Yucatán.

Bach, Emmon

1981 On Time, Tense, and Aspect: An Essay in English Metaphysics. In Radical Pragmatics. Peter Cole, ed. Pp. 63-82. New York: Academic Press.

Bohnemeyer, Jürgen

1997 Yucatec Mayan Lexicalization Patterns in Time and Space. In Proceedings of the CLS Opening Academic Year 1997-98. Monique Biemans and Joost van de Weijer, eds. Pp. 73-106. Tilburg: Center for Language Studies.

1998a Temporal Reference from a Radical Pragmatics Perspective: Why Yucatec Does

Not Need to Express "After" and "Before." Cognitive Linguistics 9(3):239-282.

1998b Time Relations in Discourse: Evidence from a Comparative Approach to Yukatek Maya. Ph.D. dissertation, Faculty of Arts, Tilburg University. 
1998c Die stellung sententialer topics im Yukatekischen (The status of sentential topics in Yucatec Maya). In Deskriptive grammatik und allgemeiner sprachvergleich (Descriptive grammar and general language comparison). Dietmar Zaefferer, ed. Pp. 55-85. Tübingen: Niemeyer.

2000 Event Order in Language and Cognition. In Linguistics in the Netherlands 17:1-16.

2002 The Grammar of Time Reference in Yukatek Maya. Munich: Lincom Europa.

Bühler, Karl

1934 Sprachtheorie: Die Darstellungsfunktion der Sprache (Linguistic theory: The representative function of language). Jena: Fischer.

Burns, Allen F.

1983 An Epoch of Miracles: Oral Literature of the Yucatec Maya. Austin: University of Texas Press.

Chung, Sandra, and Alan Timberlake

1985 Tense, Aspect, and Mood. In Language Typology and Syntactic Description. Vol. 3: Grammatical Categories and the Lexicon. Timothy Shopen, ed. Pp. 202-258. Cambridge: Cambridge University Press.

Clark, Herbert H.

1973 Space, Time, Semantics and the Child. In Cognitive Development and the Acquisition of Language. Timothy E. Moore, ed. Pp. 27-63. New York: Academic Press.

Comrie, Bernard

1976 Aspect: An Introduction to the Study of Verbal Aspect and Related Problems. Cambridge: Cambridge University Press.

1985 Tense. Cambridge: Cambridge University Press.

Dahl, Östen

1984 Temporal Distance: Remoteness Distinctions in Tense-Aspect Systems. In Explanations for Language Universals. Brian Butterworth, Bernard Comrie, and Östen Dahl, eds. Pp. 105-122. Berlin: Mouton.

Dowty, David R.

1986 The Effects of Aspectual Class on the Temporal Structure of Discourse: Semantics or Pragmatics? Linguistics and Philosophy 9(1):37-61.

Du Bois, John W.

1987 The Discourse Basis of Ergativity. Language 63(4):805-855.

Edmonson, Munro S., and Victoria R. Bricker

1985 Yucatec Mayan Literature. In Supplement to the Handbook of Middle American Indians, Vol. 3: Literatures. Munro S. Edmonson and Patricia A. Andrews, eds. Pp. 44-63. Austin: University of Texas Press.

Flint, James

1999[1998] Habitus. London: Fourth Estate.

Freed, Alice

1979 The Semantics of English Aspectual Complementation. Dordrecht: Reidel.

Hinrichs, Erhard

1986 Temporal Anaphora in Discourses of English. Linguistics and Philosophy 9 (1):63-82. Hopper, Paul J.

1979 Aspect and Foregrounding in Discourse. In Syntax and Semantics, Vol. 12: Discourse and Syntax. Talmy Givón, ed. Pp. 213-241. New York: Academic Press.

Kamp, Hans, and Christian Rohrer

1983 Tense in Texts. In Meaning, Use, and Interpretation of Language. Rainer Băuerle,

Christoph Schwartze, and Amim von Siechow, eds. Pp. 250-269. Berlin: Walter de Gruyter. 


\section{Kaufman, Terrence}

1990 Algunos rasgos estructurales de los idiomas Mayances (Some structural traits of the Mayan languages). In Lecturas sobre la Linguística Maya (Lectures on Mayan linguistics). Nora C. England and Stephen R. Elliot, eds. Pp. 59-114. La Antigua, Guatemala: Centro de Investigaciones Regionales de Mesoamérica.

Klein, Wolfgang

1992 The Present Perfect Puzzle. Language 68(3):525-552.

1994 Time in Language. London: Routledge.

Labov, William

1972 Language in the Inner City: Studies in the Black English Vernacular. Philadelphia: University of Pennsylvania Press.

Labov, William, and Joshua Waletzky

1967 Narrative Analysis: Oral Versions of Personal Experience. In Essays in the Verbal and Visual Arts. June Helm, ed. Pp. 12-44. Seattle: University of Washington Press.

Lambrecht, Knud

1994 Information Structure and Sentence Form: Topic, Focus, and the Mental Representations of Discourse Referents. Cambridge: Cambridge University Press.

Lascarides, Alex

1992 Knowledge, Causality and Temporal Representation. Linguistics 30(5):941-973.

Lascarides, Alex, and Nicholas Asher

1993 Temporal Interpretation, Discourse Relations and Commonsense Entailment. Linguistics and Philosophy 16:437-493.

Partee, Barbara Hall

1973 Some Structural Analogies between Tenses and Pronouns in English. Journal of Philosophy 70(18):601-609.

1984 Nominal and Temporal Anaphora. Linguistics and Philosophy 7(3):243-286.

Reichenbach, Hans

1947 Elements of Symbolic Logic. New York: Free Press.

Reinhart, Tanya

1984 Principles of Gestalt Perception in the Temporal Organization of Narrative Texts.

Linguistics 22:779-809.

Smith, Carlota S.

1991 The Parameter of Aspect. Dordrecht: Kluwer.

Stross, Brian

1978 Demons and Monsters: Tzeltal Tales. Museum Brief, 24: Museum of Anthropology, University of Missouri, Columbia.

Thelin, Nils B., ed.

1990 Verbal Aspect in Discourse: Contributions to the Semantics of Time and Temporal

Perspective in Slavic and Non-Slavic Languages. Amsterdam: John Benjamins.

Thompson, Sandra A.

1987 "Subordination" and Narrative Event Structure. In Coherence and Grounding in

Discourse. Russell S. Tomlin, ed. Pp. 435-454. Amsterdam: John Benjamins.

Tomlin, Russell S.

1985 Foreground-Background Information and the Syntax of Subordination. Text 5(1-2):85-122.

Traugott, Elizabeth Closs

1978 On the Expression of Spatio-Temporal Relations. In Universals of Human Language, Vol. 3: Word Structure. Joseph H. Greenberg, Charles A. Ferguson, and Edith A. Moravcsik, eds. Pp. 369-400. Stanford: Stanford University Press. 
Vapnarsky, Valentina

1999 Expressions et conceptions de la temporalite chez les Mayas Yucateques (Mexique) (Expressions and concepts of temporality among the Yucatec Mayans [of Mexicol). Ph.D. dissertation, Department of Ethnology and Comparative Sociology, Université de Paris X Nanterre.

Weinreich, Harald

1964 Tempus: Besprochene und erzählte welt (Tense: Denoted and narrated world). Stuttgart: Kohlhammer.

Department of Linguistics

University at Buffalo-SUNY

627 Baldy Hall

Buffalo, NY 14260-1030

jb77@buffalo.edu 